June 2015 Volume 2, Issue 2

(C) All rights are reserved by Bairdain et al.

\section{Revisional Bariatric Surgery}

Keywords: Revisional bariatric surgery; Excess body weight loss: Comorbid conditions

\begin{abstract}
Background: To elucidate percent excess body weight loss (\%EBWL) gained from revisional surgery and to detemine resolution of comorbid conditions given the obesity epidemic.

Methods: All patients undergoing revisional bariatric surgery from 2002 to 2012 were analyzed. Main outcome measures were \%EBWL, resolution of comorbid conditions and complications. Descriptive statistic sand paired t-tests were computed.

Results: 251 cases were performed. Initial mean body mass index was $48.1 \mathrm{~kg} / \mathrm{m}^{2}(+/-9.4)$. Hypertension (32\%) and treatment failure (37.5\%) were most commonly reported. Mean percentage difference between reoperation and last weight and original and reoperation weight was $27.9 \%$ (29.5\%), $p<0.001$. Proportions of all comorbid conditions decreased, but none statistically. No deaths occurred however $22 \%$ experienced at least one complic ation.

Conclusions: G reater \%EBWL occurs between revision surgery and last follow-up. No comorbid condition decreased. Further research is needed to detemine the optimal timing for revisional surgery to optimize \%EBWL and resolution of comorbid condition.
\end{abstract}

\section{Background}

Obesity and its associated co-morbid complications continue to increase. Severe morbid obesity is a pandemic that affects both adults and adolescents in which surgery has proven to be the only effective means to provide for long-term weight loss and apparent resolution of comorbid conditions as compared to medical management [1-4]. As acceptance of bariatric surgical interventions has increased, the numbers of both primary and revisional surgical interventions have also increased. For example, according to the American Society of Metabolic and Bariatric Surgery (ASMBS), the number of primary bariatric procedures has increased from approximately 13,000 procedures in 1998 to 220,000 procedures in 2008 respectively [5].

Revisional bariatric surgery entails knowledge of the primary surgical intervention, as well as expertise with regards to non-virginal operative fields. Herein, we aimed compare the percent excess body weight loss (\%EBWL) and body mass index (BMI) between each bariatric procedure, as well between primary, revisional procedure, and final outcome measures. Secondary aims included identifying whether there was a particular bariatric operation that predicted a higher resolution of comorbid conditions and predicted less associated complications.

\section{Methods}

Following institutional board approval, data from a retrospective case review of all patients undergoing revisional bariatric surgical interventions, excluding port revisions of laparoscopic gastric banding procedures (LAGB), at one academic medical center were analyzed from a prospective, longitudinal database. Information from 2002 to 2012 was collected. Demographic, clinical, co-morbid conditions and complications were compared between revisional groups. Weight loss was expressed as percent excess body weight loss (\%EBWL), defined as the difference between initial weight and

\section{Journal of Obesity and Bariatrics}

Sigrid Bairdain ${ }^{1 *}$, Mark Cleary ${ }^{2}$, Heather J. Litman ${ }^{3}$, Bradley C. Linden ${ }^{4}$ and David B. Lautz ${ }^{5}$

${ }^{1}$ Department of Surgery, Boston Children's Hospital, Boston, MA, USA

${ }^{2}$ Department of Surgery, Brigham and Women's Hospital, Boston, MA, USA

${ }^{3}$ Clinical Research Center, Boston Children's Hospital, Boston, MA, USA

${ }^{4}$ Pediatric Surgical Associates, Children's Hospitals and Clinics of Minnesota, Minneapolis, MN, USA

${ }^{5}$ Department of Surgery, Emerson Hospital-Harvard Medical School, Concord, MA, USA

\section{*Address for Correspondence}

Sigrid Bairdain, MD, MPH, Surgical Research Fellow, Department of Surgery, Boston Children's Hospital, 300 Longwood Avenue, Fegan Building, 3rd Floor, Boston, MA 02115, USA, E-mail: Sigrid.bairdain@childrens.harvard.edu

Copyright: (c) 2015 Bairdain S, et al. This is an open access article distributed under the Creative Commons Attribution License, which permits unrestricted use, distribution, and reproduction in any medium, provided the original work is properly cited.

Submission: 15 May 2015

Accepted: 15 June 2015

Published: 20 June 2015

Reviewed \& Approved by: Dr. Francesco Saverio Papadia, Assistant Professor of Surgery, University of Genoa School of Medicine, Italy

Dr. Radwan Kassir, Department of General and Bariatric surgery, University Hospital Center of Saint-Étienne, France

current weight, divided by the difference of the initial weight and ideal weight. The ideal body weight and was calculated from the 1983 Metropolitan Life Insurance Company tables [6]. Percent EBWL was calculated at each revision and last clinic visit. The main outcome measure was \%EBWL. Secondary outcome measures included resolution of comorbid conditions and associated complications.

For the purposes of this study, patients were grouped into 4 revision types: 1) conversion from one bariatric surgical procedure to another; 2) revision of a previous operation with no conversion; 3) reversal and 4) exploration. Conversion surgeries included: GP-to Laparoscopic Roux-en-Y Gastric Bypass (LRYGB), Jejunoileal Bypass (JIB) to LRYGB, Laparoscopic Adjustable Gastric Banding (LAGB) to LRYGB, LAGB to Laparoscopic Sleeve Gastrectomy (LSG), and Vertical Banded Gastroplasty (VBG) to LRYGB. Revisional surgeries included: open revision bypass, open revision jejunojejunal (JJ), laparoscopic revision JJ, and laparoscopic revision bypass. Reversal surgeries included: open reversal RYGB, laparoscopic reversal RYGB, reversal VBG, and open Entero Cutaneous-Fistula (ECF) takedown. Overall indications for revision were divided into the following categories: 1) pain; 2) obstruction; 3) failure to thrive; 4) development of an enterocutaneous fistula; 5) treatment failure; 6) gastrointestinal issues primarily related to gastroesophageal reflux and ulcers and 7) medically or nutritional-related issues.

All patients met the criteria for bariatric surgery established by the National Institutes of Health Consensus Development Panel with patients having a body mass index (BMI) of $>40 \mathrm{~kg} / \mathrm{m}^{2}$, or $>35 \mathrm{~kg} /$ $\mathrm{m}^{2}$ in the presence of obesity related comorbidities. All had failed to maintain weight loss by non-surgical means. All patients were 
required to attend a public information session given by one of the surgeons and be assessed by both a clinical psychiatrist and dietician.

Preoperative investigations were guided by the patient history and type of surgery. Routine investigations included an upper gastrointestinal barium study for all patients. The decision for each particular revisional surgical intervention was made by the patient after an extensive period of counseling and education. Revisional bariatric patients were recovered in a surgical ward by staff experienced in management of postoperative bariatric patients. All patients were reviewed in outpatient clinic at 2 weeks, as well as regularly assessed for vitamin and mineral deficiencies and treated accordingly. Descriptive statistics for continuous and categorical variables were presented, as appropriate. Paired t-tests were computed to assess outcome measure differences between original and last follow-up.

\section{Results}

From 2002-2012, a total of 251 revisional bariatric operations were performed, $28 \%$ of which underwent more than one subsequent operation. Baseline demographic data was included in Table 1. Eighty-five percent $(n=213)$ were female. Mean age at the time of the original operation was 39 years (+/- 12 years) (Table 1$)$. The most common (51\%) original operation was a Laparoscopic Roux-En-Y Gastric Bypass (RYGB). The most common indication for revision of the primary surgical procedure was treatment failure/failure to lose weight $(n=94,37.5 \%)$; other etiologies found independently or concurrently included fistulas $(\mathrm{n}=84,33.5 \%)$ and previous technical complications ( $\mathrm{n}=31,12.4 \%)$. Of note, the majority of fistulas (gastrogastric fistulas) were identified concurrently during the revision for treatment failure/failure to lose weight (Table 1).

Approximately 6.5\% ( $\mathrm{n}=97 / 251)$ were considered conversion surgeries, $55 \%(n=139 / 251)$ were considered revisional surgeries, $2.7 \%(\mathrm{n}=7 / 251)$ were considered reversal surgeries and $1.5 \%$ $(n=4 / 251)$ were considered exploratory surgeries (Table 2A). Ninety percent $(n=226)$ of the operations were performed laparoscopically. At the time of the original operation, mean body mass index (BMI) was $48.1 \mathrm{~kg} / \mathrm{m}^{2}(+/-9.4)$ and decreased on average to $40.4 \mathrm{~kg} / \mathrm{m}^{2}(+/-$ 10.4) prior to the first re-operative surgery and $34.0 \mathrm{~kg} / \mathrm{m}^{2}(+/-8.8)$ at the last hospital visit (Table 2B). The mean difference, in pounds (lbs), between pre-reoperation and original was 7.7 lbs. (s.d. 8.4 lbs, $\mathrm{p}<0.001$, paired t-test) and between last clinic visit and original operation was $14.1 \mathrm{lbs}$ (s.d. $7.3 \mathrm{lbs}, \mathrm{p}<0.001$, paired t-test). The mean percentage difference between reoperation and last weight (\%EBWL) and original and reoperation weight (\%EBWL) was $27.9 \%$ (29.5\%, p $<0.001$, paired t-test).

The most common comorbid conditions were hypertension (32\%), obstructive sleep apnea (21\%), asthma (19\%) and diabetes $(18 \%)$ (Table 1). There was a decrease in the proportions of all comorbid conditions between the original and last visit, but none reached statistical significance. At the original operation, 41/224 (18.3\%) had Diabetes Mellitus (DM). At first revision, 41/249 (16.5\%) had DM, whereas, at last visit, 24/236 (10.2\%) had DM. The procedure with the largest proportional change of DM was the laparoscopic conversion of the laparoscopic-adjusted gastric banding (LAGB surgery) to Roux-En-Y Gastric Bypass (RYGB); however, this difference did not reach statistical significance $(\mathrm{p}=0.47)$ (Table 3 ).
Table 1: Preliminary descriptive information regarding the dataset $(n=251)$.

\begin{tabular}{|c|c|}
\hline Characteristic & $\begin{array}{c}\text { N (\%) or Mean (standard } \\
\text { deviation) }\end{array}$ \\
\hline Gender (female) & $213(84.9 \%)$ \\
\hline Age at original surgery & $39.2(11.7)$ \\
\hline \multicolumn{2}{|l|}{ Original surgery type } \\
\hline VBG & $9(3.6 \%)$ \\
\hline LAGB & $88(35.1 \%)$ \\
\hline LRYGB & $128(51.0 \%)$ \\
\hline Open RYGB & $22(8.8 \%)$ \\
\hline Other & $4(1.5 \%)$ \\
\hline Original weight & $291.3(66.4)$ \\
\hline Original height & $65.2(3.6)$ \\
\hline Original Body Mass Index (BMI) & $48.1(9.4)$ \\
\hline Ideal Body Weight (IBW) & $135.6(12.3)$ \\
\hline DM & $41(18.3 \%)$ \\
\hline HTN & $72(31.9 \%)$ \\
\hline OSA & $48(21.4 \%)$ \\
\hline Asthma & $42(18.9 \%)$ \\
\hline Age at second operation & $45.1(10.7)$ \\
\hline Weight at reoperation & $245.4(71.9)$ \\
\hline Body Mass Index (BMI) at reoperation & $40.4(10.4)$ \\
\hline \%EBWL & $30.4(33.7)$ \\
\hline DM at second operation & $41(16.5 \%)$ \\
\hline HTN at second operation & $81(32.5 \%)$ \\
\hline OSA at second operation & $56(22.5 \%)$ \\
\hline ASH at second operation & $40(16.1 \%)$ \\
\hline \multicolumn{2}{|l|}{ Indication for Revision } \\
\hline Pain & $14(5.6 \%)$ \\
\hline Obstruction or Technical & $31(12.4 \%)$ \\
\hline Failure to thrive & $3(1.2 \%)$ \\
\hline Fistula & $84(33.5 \%)$ \\
\hline Treatment Failure & $94(37.5 \%)$ \\
\hline Gastrointestinal issues & $6(2.4 \%)$ \\
\hline Medical protracted issues & $19(7.6 \%)$ \\
\hline Perioperative complications & $54(21.5 \%)$ \\
\hline DM at third operation & $24(10.2 \%)$ \\
\hline HTN at third operation & $47(19.9 \%)$ \\
\hline OSA at third operation & $29(12.2 \%)$ \\
\hline Surgical time (minutes) & $234(90)$ \\
\hline Length of stay & Median (IQR): $3(2,5)$ \\
\hline Length of follow-up (mos.) & Median (IQR): $11(5,27)$ \\
\hline Last weight & $206.4(59.9)$ \\
\hline Last Body Mass Index (BMI) & $34.0(8.8)$ \\
\hline Last \%EBWL & $58.3(32.2)$ \\
\hline Estimated blood loss* & $155.7(29.0)$ \\
\hline
\end{tabular}

*Median (IQR): 0 (0,300); VBG: Vertical Banding; LAGB: Laparoscopic Gastric Banding; LRYGB: Laparoscopic Roux-En-Y Gastric Bypass; Open RYGB: Open Roux-en-Y Gastric Bypass; DM: Diabetes; Mellitus; HTN: Hypertension; OSA: Obstructive Sleep Apnea; \%EBWL: Percent Excess Body weight loss 
ISSN: $2377-9284$

Table 2A: Indications and procedures performed for bariatric cohort.

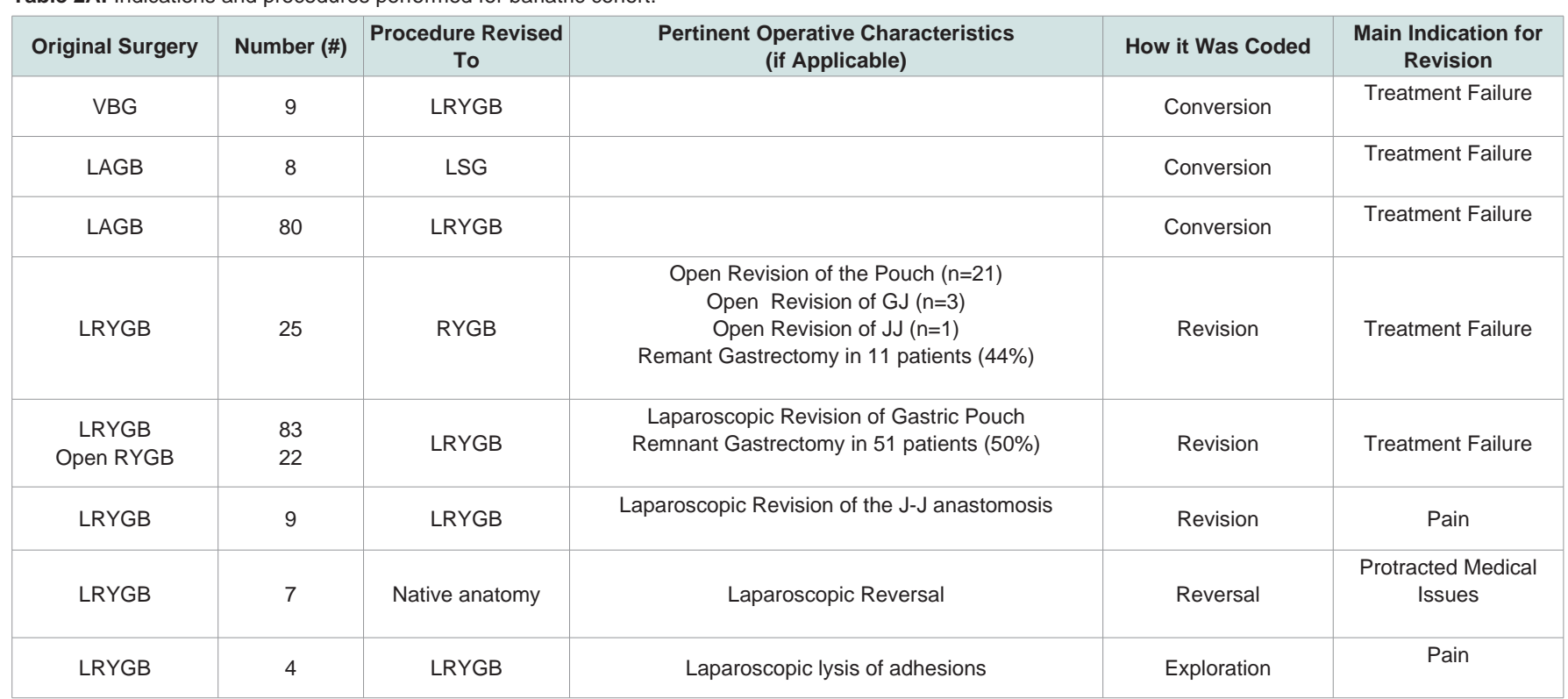

BMI: Body Mass Index; VBG: Vertical Banding; LAGB: Laparoscopic Gastric Banding; LSG: Laparoscopic Sleeve; LRYGB: Laparoscopic Roux-en-Y gastric Bypass; Open RYGB: Open Roux-en-Y Gastric Bypass

Table 2B: BMI changes over time and per operative intervention.

\begin{tabular}{|c|c|c|c|}
\hline & & \multicolumn{2}{|c|}{ Mean (standard deviation) } \\
\hline Operations & N & $\begin{array}{c}\text { Between original and pre- } \\
\text { reoperation }\end{array}$ & $\begin{array}{c}\text { Between pre-reoperation } \\
\text { and last }\end{array}$ \\
\hline VBG & 9 & $4.4(5.9)$ & $10.5(6.2)$ \\
\hline LAGB & 88 & $2.9(4.5)$ & $8.5(5.0)$ \\
\hline LRYGB & 128 & $10.6(9.0)$ & $4.6(6.7)$ \\
\hline Open RYGB & 22 & $11.0(7.2)$ & $11.4(5.6)$ \\
\hline Other & 4 & $2.9(7.9)$ & $15.2(8.3)$ \\
\hline
\end{tabular}

BMI: Body mass Index; VBG: Vertical Banding; LAGB: Laparoscopic Gastric Banding; LRYGB: Laparoscopic Roux-en-Y Gastric Bypass; Open RYGB: Open Rouxen-Y Gastric Bypass

Regarding hypertension, 72/226 (31.9\%) reported it originally, $81 / 249(32.5 \%)$ had it at first revision and $47 / 236(19.9 \%)$ at the final visit. Comparing those who had hypertension at last follow-up to the others, the percentages are quite similar between the various operations ( $\mathrm{p}=0.68)$. Regarding OSA, 48/224 (21.4\%) reported it originally, 56/249 (22.5\%) had it at first revision and 29/237 (12.2\%) had it a last visit. Of those with improved OSA status, LAGB has a slightly higher proportion that those with no change in OSA status $(\mathrm{p}=0.26)$. Regarding asthma, 42/224 $(18.8 \%)$ reported it originally, $40 / 249(16.1 \%)$ had it at first revision and 22/237 (9.3\%) had it a last visit. Among those with improved asthma status, most either had LAGB or LRYGB surgeries and this was similar to those without improved asthma status $(\mathrm{p}=0.73)$ (Table 3$)$.

Median intraoperative time was 234 minutes and median length of hospital stay was 3 days (range 2-5 days) (Table 1). Overall, there were $21.5 \%$ of cases that had perioperative complications (54/251); however, no deaths occurred. The distributions with and without complications differ according to surgery type (Fisher's exact test, $\mathrm{p}<0.001)$. Among those who had complications, the highest proportion of complications occurred within LRYGB and included postoperative bleeding and obstruction (Table 4).

\section{Discussion}

Revisional bariatric surgery is now commonplace. In our study, it appears that greater \%EBWL occurred between revision surgery and last clinic visit than between the original surgery and first reoperation. There was not a single comorbid condition that decreased statistically significantly during the study period; however, all of them had a downward trend. Overall, complications did occur; however, there was no mortalities reported. These results are not unlike contemporary research on revisional bariatric surgery. The reported incidence of reoperation in bariatric surgery ranges from $5-57 \%$, but the quality and integrity of what is reported is sometimes questioned [3,7-9]. Previous studies have grouped their patients based on the etiologies for revisional surgery [10]. However, given that a majority of our patients were referred to a tertiary weight loss center for inadequate weight loss, we chose to group our patients based on the type of revision surgery performed. The majority of our patients benefitted from either laparoscopic conversion of their primary procedure to a RYGB or revision of their primary procedure. Success, as defined by a $\% \mathrm{EBWL}>50$, was achieved in our cohort at the last clinic visit (\%EBWL of 58.3\%) and was consistent with current literature on the 
Tables 3A-3D: Changes in Percentages (\%) of Comorbid Conditions over time and per Operation

\begin{tabular}{|c|c|c|}
\hline \multicolumn{3}{|c|}{ Diabetes (DM) } \\
\hline Surgery type & No change in DM status & Improved DM status \\
\hline VBG & $3(1.6 \%)$ & 0 \\
\hline LAGB & $67(34.9 \%)$ & $9(52.9 \%)$ \\
\hline LRYGB & $98(51.0 \%)$ & $8(47.1 \%)$ \\
\hline Open RYGB & $22(11.5 \%)$ & 0 \\
\hline \multicolumn{3}{|c|}{ Hypertension } \\
\hline Surgery type & $\begin{array}{c}\text { No change in } \\
\text { hypertension status }\end{array}$ & $\begin{array}{c}\text { Improved hypertension } \\
\text { status }\end{array}$ \\
\hline VBG & $3(1.7 \%)$ & 0 \\
\hline LAGB & $65(37.4 \%)$ & $13(35.1 \%)$ \\
\hline LRYGB & $87(50.0 \%)$ & $19(51.4 \%)$ \\
\hline Open RYGB & $18(10.3 \%)$ & $4(10.8 \%)$ \\
\hline \multicolumn{3}{|c|}{ Obstructive Sleep Apnea } \\
\hline Surgery type & $\begin{array}{c}\text { No change in OSA } \\
\text { status }\end{array}$ & Improved OSA status \\
\hline VBG & $3(1.7 \%)$ & 0 \\
\hline LAGB & $63(35.0 \%)$ & $14(46.7 \%)$ \\
\hline LRYGB & $92(51.1 \%)$ & $14(46.7 \%)$ \\
\hline Open RYGB & $21(11.7 \%)$ & $1(3.3 \%)$ \\
\hline \multicolumn{3}{|c|}{ Asthma } \\
\hline Surgery type & $\begin{array}{c}\text { No change in Asthma } \\
\text { status }\end{array}$ & $\begin{array}{c}\text { Improved Asthma } \\
\text { status }\end{array}$ \\
\hline VBG & $3(1.7 \%)$ & 0 \\
\hline LAGB & $65(35.7 \%)$ & $12(42.9 \%)$ \\
\hline LRYGB & $91(50.0 \%)$ & $15(53.6 \%)$ \\
\hline Open RYGB & $21(11.5 \%)$ & $1(3.6 \%)$ \\
\hline
\end{tabular}

VBG: Vertical Banding; LAGB: Laparoscopic Gastric Banding; LRYGB Laparoscopic Roux-en-Y Gastric Bypass; Open RYGB: Open RouX-en-Y Gastric Bypass; DM: Diabetes Mellitus; HTN: Hypertension; OSA: Obstructive Sleep Apnea

Table 4A: Complication data.

\begin{tabular}{|c|c|c|}
\hline Surgery type & No complications & Complications \\
\hline VBG & $8(4.1 \%)$ & $1(1.9 \%)$ \\
\hline LAGB & $82(41.6 \%)$ & $6(11.1 \%)$ \\
\hline LRYGB & $89(45.2 \%)$ & $39(72.2 \%)$ \\
\hline Open RYGB & $17(8.6 \%)$ & $5(9.3 \%)$ \\
\hline
\end{tabular}

Among those who had complications, the highest proportion was of type LRYGB. The distributions with and without complications differ according to surgery type (Fisher's exact test, $\mathrm{p}<0.001$ ).

VBG: Vertical Banding; LAGB: Laparoscopic Gastric Banding; LRYGB: Laparoscopic Roux-en-Y Gastric Bypass; Open RYGB: Open Roux-en-Y gastric Bypass

Table 4B: Complication data.

\begin{tabular}{|c|c|c|}
\hline Revision Surgery type & No complications & Complications \\
\hline Conversion & $91(46.2 \%)$ & $9(16.7 \%)$ \\
\hline Revision & $100(50.8 \%)$ & $44(81.5 \%)$ \\
\hline Reversal & $3(1.5 \%)$ & $1(1.9 \%)$ \\
\hline Lap Exploration & $3(1.5 \%)$ & 0 \\
\hline
\end{tabular}

Among those who had complications, $82 \%$ were revisions which was different from those with no complications (Fisher's exact test, $p<0.001$ ). effectiveness of transitioning or revising the roux-en $\mathrm{Y}$ gastric bypass $[3,8,10-14]$.

Unlike other contemporary literature, there appeared to be fewer revisions for gastrointestinal complaints, failure to thrive or medicallyprotracted conditions $[3,15,16]$. The percentages of revision cases in our cohort for technical and mechanical complications, as well as fistulas, were consistent with previously reported literature with most cases attempted laparoscopically [3,10,17]. It was interesting that fistulas were often found concurrently with treatment failure cases; however, further studies are needed to elucidate whether this plays a larger role in weight loss in our cohort. We did not necessarily see an increased rate of complications with performing these operations laprascopically, as revisional bariatric surgery is often quoted as having a complication rate of between $10-50 \%[8,10,18,19]$. Our complication was approximately $22 \%$, albeit, $28 \%$ of our cohort had more than one operation. We believe that this approach may be taken and does not necessarily increase the rate of complication at high-volume centers. Juxtaposed to the previously reported operative mortality rates of less than $2.5 \%$, we had no mortalities in our series $[8,10,11,13]$.

Surprisingly none of our comorbid medical conditions reached a statistical significant decrease following re-operations. According to one of the most recent review papers by the American Society for Metabolic and Bariatric Surgery Revision Task Force, resolution of comorbid conditions must be considered as important as and/ or more important than reduction in \%EBWL and BMI [9]. Given that our study had a shorter follow-up, these conditions may become significant over time. Further long-term studies are needed to elucidate this.

Despite this study's strengths, one limitation is that given our institution is a tertiary referral facility, often we cannot control for loss to follow up, especially in the setting of a retrospective study following revision surgeries. Attrition is not uncommon following bariatric surgery and is possibly related to durable weight loss. In addition, since we are a high volume referral center, some patients choose to establish follow up care with bariatric surgeons closer to home and we do not have the long-term data on co-morbid conditions and longerterm \%EBWL.

\section{Conclusion}

Revisional bariatric surgery is now a commonplace surgical intervention. Greater \%EBWL occurs between revision surgery and last clinic visit than between the original surgery and reoperation. No single comorbid condition reached statistical significance during the study period; however, there was an overall decrease in the rates of hypertension, diabetes and obstructive sleep apnea. Further research is needed to determine the optimal timing for revisional bariatric surgery once initial treatment has failed to optimize excess weight loss and resolution of comorbid conditions.

\section{References}

1. Maggard MA, Shugarman LR, Suttorp M, Maglione M, Sugerman HJ, et al. (2005) Meta-analysis: surgical treatment of obesity. Ann Intern Med 142: 547559.

2. Sjöström L, Lindroos AK, Peltonen M, Torgerson J, Bouchard C, et al. (2004) Lifestyle, diabetes, and cardiovascular risk factors 10 years after bariatric surgery. N Engl J Med 351: 2683-2693. 
Citation: Bairdain S, Cleary M, Litman HJ, Linden BC, Lautz DB. Revisional Bariatric Surgery. J Obes Bariatrics. 2015;2(2): 5.

3. Spyropoulos C, Kehagias I, Panagiotopoulos S, Mead N, Kalfarentzos F (2010) Revisional bariatric surgery: 13-year experience from a tertiary Institution. Arch Surg 145: 173-177.

4. Colquitt JL, Pickett K, Loveman E, Frampton GK (2014) Surgery for weight loss in adults. Cochrane Database Syst Rev 8: CD003641.

5. Madura JA 2 ${ }^{\text {nd }}$, Dibaise JK (2012) Quick fix or long-term cure? Pros and cons of bariatric surgery. F1000 Med Rep 4: 19.

6. (1983) 1983 metropolitan height and weight tables. Stat Bull Metrop Life Found 64: 3-9.

7. Buckwalter JA, Herbst CA Jr, Khouri RK (1985) Morbid obesity: second gastric operations for poor weight loss. Ann Surg 51: 208-211.

8. van Gemert WG, van Wersch MM, Greve JW, Soeters PB (1998) Revisional surgery after failed vertical banded gastroplasty: restoration of vertical banded gastroplasty or conversion to gastric bypass. Obes Surg 8: 21-28.

9. Brethauer SA, Kothari S, Sudan R, Williams B, English WJ, et al. (2014) Systematic review on reoperative bariatric surgery: American Society for Metabolic and Bariatric Surgery Revision Task Force. Surg Obes Relat Dis 10: $952-972$

10. Nesset EM, Kendrick ML, Houghton SG, Mai JL, Thompson GB, et al. (2007) A two-decade spectrum of revisional bariatric surgery at a tertiary referral center. Surg Obes Relat Dis 3: 25-30.

11. Behrns KE, Smith DC, Kelly KA, Sarr MG (1993) Reoperative bariatric surgery. Lessons learned to improve patient selection and results. Ann Surg 218: 646-653.
12. Fobi MA, Lee H, Igwe D Jr, Felahy B, James E, et al. (2001) Revision of failed gastric bypass to distal Roux-en-Y gastric bypass: a review of 65 cases. Obes Surg 11: 190-195.

13. Jones KB Jr (2001) Revisional bariatric surgery--safe and effective. Obes Surg 11: 183-189.

14. Westling A, Ohrvall M, Gustavsson R (2002) Roux-en-Y gastric bypass after previous unsuccessful gastric restrictive surgery. J Gastrointest Surg 6: 206211.

15. Skroubis G, Anesidis S, Kehagias I, Mead N, Vagenas K, et al. (2006) Rouxen-Y gastric bypass versus a variant of biliopancreatic diversion in a nonsuper obese population: prospective comparison of the efficacy and the incidence of metabolic deficiencies. Obes Surg 16: 488-495.

16. Skroubis G, Sakellaropoulos G, Pouggouras K, Mead N, Nikiforidis G, et al. (2002) Comparison of nutritional deficiencies after Roux-en-Y gastric bypass and after biliopancreatic diversion with Roux-en-Y gastric bypass. Obes Surg 12: $551-558$

17. Papasavas PK, Caushaj PF, McCormick JT, Quinlin RF, Hayetian FD, et al. (2003) Laparoscopic management of complications following Roux-en-Y gastric bypass for morbid obesity. Surg Endosc 17: 610-614.

18. Schwartz RW, Strodel WE, Simpson We, Griffen WO Jr (1998) Gastric bypass revision: lessons learned from 920 cases. Surgery 104: 806-812.

19. Benotti PN, Forse RA (1996) Safety and long-term efficacy of revisional surgery in severe obesity. Am J Surg 172: 232-235. 